Int. J. Dev. Biol. 59: 453-460 (2015)

doi: $10.1387 / \mathrm{ijdb} .140287 \mathrm{ct}$

\title{
Chicken primordial germ cell motility in response to stem cell factor sensing
}

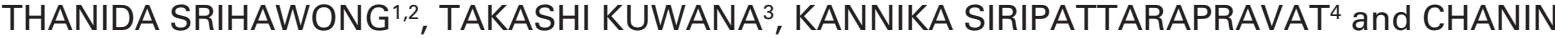 \\ TIRAWATTANAWANICH ${ }^{5}$ \\ ${ }^{1}$ Center for Agricultural Biotechnology, Kasetsart University, NakhonPathom, Thailand, ${ }^{2}$ Center of Excellence on Agricultural \\ Biotechnology (AG-BIO/PERDO-CHE), Bangkok, Thailand, ${ }^{3}$ International Institute of Avian Conservation Science, MNC, Department \\ of the President's Affairs, United Arab Emirates, 'Department of Pathology, Faculty of Veterinary Medicine, Kasetsart University, \\ Bangkok, Thailand and ${ }^{5}$ Department of Physiology, Faculty of Veterinary Medicine, Kasetsart University, Bangkok, Thailand
}

\begin{abstract}
Avian primordial germ cells (PGCs) are destined to migrate a long distance from their extra embryonic region via the vascular system to the gonadal ridges where they form the germ cells. Although PGC migration is crucial for a genetic continuation to the next generation, the factors and mechanisms that control their migration remain largely unknown. In the present study the chemotactic effect of stem cell factor (SCF) was examined on chicken blood circulating PGCs (cPGC), employing 3D chemotaxis slides and time-lapsed imaging analyses as an in vitro study model. Upon in vitro exposure to an SCF gradient, $77.1 \%$ (54 out of 70 ) of cPGCs showed a clear response, of which $48.1 \%$ (26 out of 54 ) polarized with the consecutive formation of a persistent membrane protrusion and significant directional migration towards the gradient and the others showed transient membrane protrusions. In contrast, the controls and apparently SCF unresponsive cPGCs and c-kit-negative red blood cells (RBCs) showed only cytoplasmic cycling with random formations of membrane blebbing and no directional migration. Significant $(p<0.05)$ differences between the SCF-treated and control cPGCs and RBCs were found in the migration parameters of eccentricity, accumulated and Euclidean distances, and migration velocity. The SCF-treated PGCs also revealed a chemotactic response, as judged by their significant displacement of center of mass and Rayleigh test. Complete inhibition of all the SCF-induced responses in PGCs was found following pretreatment of the cPGCs with $10 \mu \mathrm{M}$ of the c-kit inhibitor, STI57I, prior to SCF exposure. In addition, cPGCs were found to be positive for c-kit expression using a polyclonal goat anti-mouse c-kit primary antibody, suggesting that the cPGCs were capable of SCF sensing and the potential involvement of SCF/c-kit in the chemotactic migration. Therefore, SCF is suggested to function as a chemoattractant in the migration of chicken cPGC.
\end{abstract}

KEY WORDS: Chicken primordial germ cell, chemotaxis, stem cell factor, c-kit receptor, migration

\section{Introduction}

Primordial germ cells (PGCs) are pluripotent stem cells that give rise to functional gametes through sequential differentiation inside the gonads (Matsui et al., 1992). Unlike mammals, avian PGCs migrate a long distance from their extra embryonic region to the presumptive gonads via the vascular system. Based on positive periodic acid Schiff (PAS) staining and the positive expression of stage-specific embryonic antigen-1 (SSEA-1) characteristics, avian PGCs have been identified as being of an extra-embryonic origin (Eyal-Giladi et al., 1981). Chicken PGCs scattered in the central area of blastoderm at stage X, PGCs transmigrate into the blood- stream at the anterior vitelline vein and leave the bloodstream for the gonadal anlagen as early at stages 10 and 15 (Nakamura et al., 2007), respectively. The gonadal migration of the circulating PGCs (cPGCs) appears to be carried out by active migration with specific guidance and not by random passive migration (Kuwana et al., 1986). The controlling factors as well as the induction mechanisms are, however, largely unknown. Chemokines attracting PGC migration towards the gonadal anlagen remain to be explored in avian.

Mammalian PGCs originate posteriorly in the extra-embryonic

Abbreviations used in this paper: cPGC, circulating primordial germ cell; SDF-1, stromal cell derived factor-1; SCF, stem cell factor. *Address correspondence to: ChaninTirawattanawanich, Department of Physiology, Faculty of Veterinary Medicine, Kasetsart University, Bangkok 10900,Thailand.
Fax: +662-5797538; E-mail: fvetcnt@ ku.ac.th

Accepted: 19 June 2015. Edited by: Sally Dunwoodie

ISSN: Online 1696-3547, Print 0214-6282 


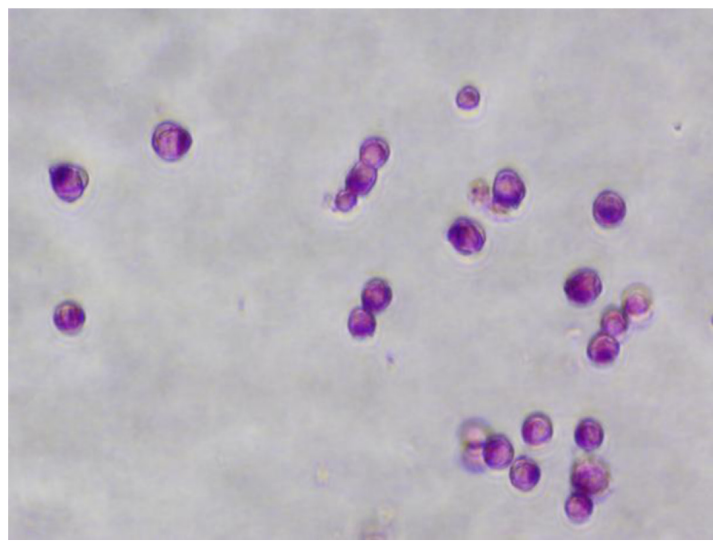

Fig. 1. Periodic Acid Schiff (PAS) staining of paraformaldehyde-fixed blood cPGCs collected from chicken embryos at stages 14-15 of development. Numerous PAS-positive cytoplasmic granules were evident in most cells.

region neighboring the future gonads and migration to the genital ridges is achieved by migrating along the hindgut and the dorsal mesentery (Anderson et al., 2000). Guiding factors in mammal PGC migration, including stromal cell derived factor-1 (SDF-1), stem cell factor (SCF), e-cadherin, laminin and fibronectin, have been reported to function as either chemokinetic, chemotactic or adhesion molecules (reviewed in (Soto-Suazo and Zorn, 2005)). However, the migratory route of avian PGCs differs from that of mammalian ones. With different means of migration, the controlling factors and mechanisms currently known in mammals can not be generally assumed to apply in the avian case and so they need to be specifically examined. Major chemoattractants contributing to PGC migration in mouse and human include SDF-1 (Ara et al., 2003) and SCF (Gu et al., 2009; Mamsen et al., 2012), but only SDF-1 has been suggested to direct the late-phase migration of avian PGCs (Stebler et al., 2004). This leaves the question as to whether other factors are involved in the migration of avian cPGCs.
Chemotactic molecules cause activated migratory cells to polarize and gain motility and directional sensing towards the specific destination (reviewed in (Iglesias and Devreotes, 2008)). Chemoattractants are believed to be a crucial factor guiding PGC migration towards the genital ridges. Displacement and failure of PGCs to reach the target organ may cause infertility due to defective germ cell production. In the Aves case, SDF-1 is the only chemokine currently suggested to play a chemotactic role in the late circulation of chicken cPGCs towards developing gonads (Stebler et al., 2004).

SCF has been reported to be a pleiotropic factor involved in cell survival, proliferation, development and migration (reviewed in (Lennartsson and Ronnstrand, 2012)). The chemotactic function of SCF on PGC migration, established in mice and humans (Farini et al., 2007; Gu et al., 2009; Mamsen et al., 2012), has not yet been revealed in Aves. Noticeably, during chicken early embryonic development, SCF is strongly expressed in the lateral and intermediate mesoderm regions (Reedy et al., 2003), part of which later contributes to the development of the gonadal anlagen. It is feasible that SCF could be a chemotactic molecule released by the gonadal anlagen to attract chicken CPGC migration during embryogenesis. Therefore, we aimed to explore the chemotactic action of SCF on chicken CPGC migration in vitro.

\section{Results}

\section{PGC isolation, enrichment and characterization}

Approximately 100-250 enriched cPGCs per embryo were obtained. The CPGC morphology remained well defined and clearly distinguishable from blood cells following nycodenz density gradient purification. The enriched cells were PAS positive with a pink-staining cytoplasm (Fig.1), whilst the SSEA-1 immunofluorescent staining was strongly positive (Fig. $2 \mathrm{~A}-\mathrm{D}$ ), confirming that the enriched cells were cPGCs without any detectable blood cell contamination. The polyclonal anti-mouse $c$-kit revealed a positive expression of the c-kit antigen on the cellular membrane of all
Fig. 2. Microscopic images $(400 x$ magnification) of paraformaldehyde-fixed blood cPGCs collected from chicken embryos at stages14-15 of development. (A,E) Phase-contrast images showing large spherical shaped cells with cytoplasmic granules and eccentric nuclei. (B) Indirect immunofluorescentstaining using monoclonal mouse anti-SSEA-1 $\lg M$ and FITC-conjugated goat anti-mouse IgM primary and secondary antibodies, respectively. $(\mathbf{C}, \mathbf{G})$ Nuclear counterstaining with Hoechst 33342. (D) Merged images of PGCs with positive SSEA-1 (green color) and nuclear staining (dark blue color). (F) Indirect immunofluorescent staining using polyclonal goat anti-mouse

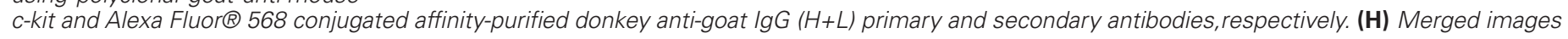
of PGCs with c-kit positive (red color) and nuclear staining (dark blue color). Image format was pixels. Scale bars represent $20 \mu \mathrm{m}$.
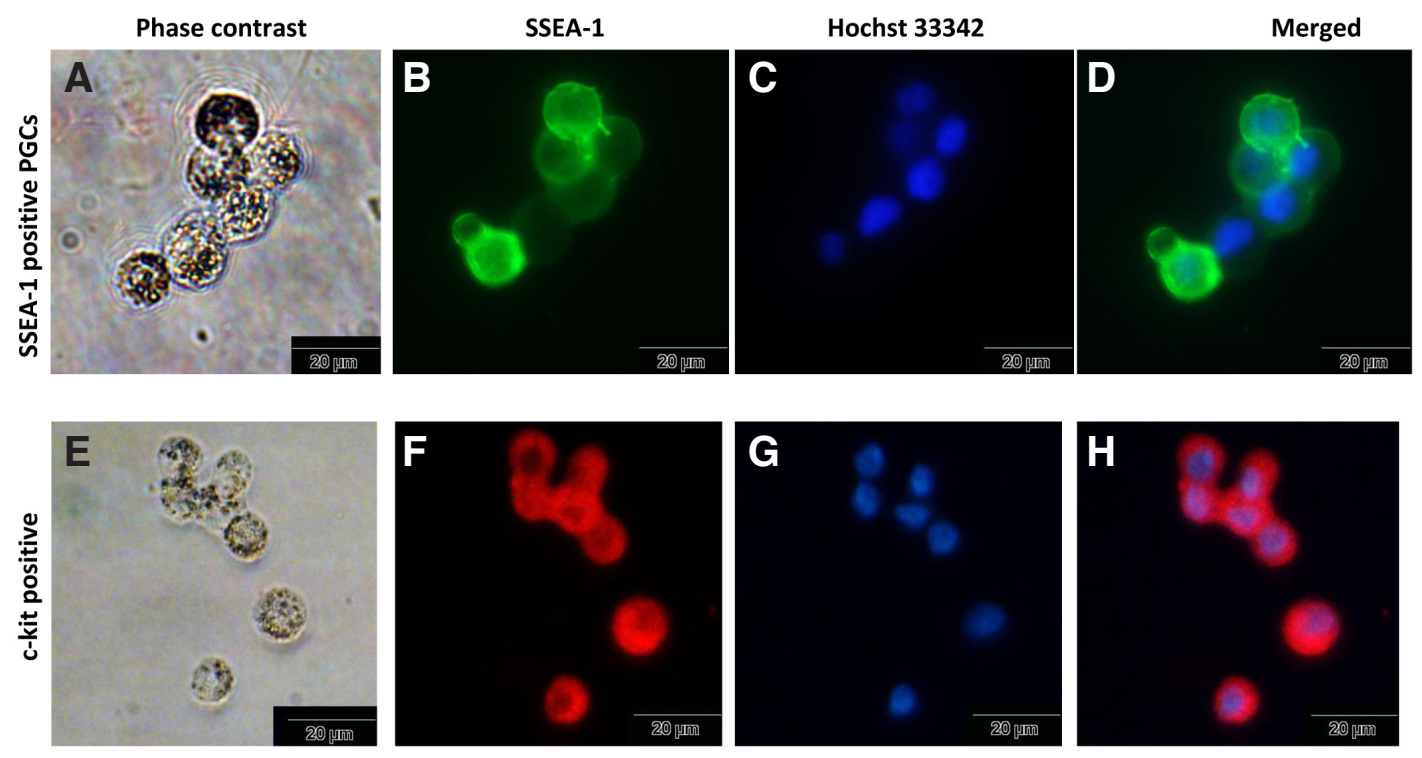
TABLE 1

\section{MIGRATION INDEX}

\begin{tabular}{lcccc} 
Treatment group & $\begin{array}{c}\text { Total number } \\
\text { of PGCs }\end{array}$ & $\begin{array}{c}\text { Accumulated } \\
\text { distance }(\mu \mathrm{m})\end{array}$ & $\begin{array}{c}\text { Euclidean } \\
\text { distance }(\mu \mathrm{m})\end{array}$ & $\begin{array}{c}\text { Velocity } \\
(\mathrm{nm} / \mathrm{min})\end{array}$ \\
\hline Control cPGCs & 51 & $2.19 \pm 0.49^{\mathrm{b}}$ & $1.83 \pm 0.42^{\mathrm{b}}$ & $3 \pm 1^{\mathrm{b}}$ \\
SCF-treated RBCs & 118 & $3.98 \pm 0.38^{\mathrm{D}}$ & $3.05 \pm 0.30^{\mathrm{D}}$ & $2 \pm 1^{\mathrm{D}}$ \\
SCF-treated CPGCs & 70 & $209.22 \pm 26.88^{\mathrm{a}}$ & $44.35 \pm 7.35^{\mathrm{a}}$ & $251 \pm 31^{\mathrm{a}}$ \\
STI571-pretreated CPGCs & 64 & $2.69 \pm 1.57^{\mathrm{b}}$ & $1.12 \pm 0.27^{\mathrm{b}}$ & $1 \pm 1^{\mathrm{b}}$ \\
\hline
\end{tabular}

Data are shown as the mean \pm SEM, derived from three replications.

a,b Means with different superscript letters within a column are significantly different $(p<0.05)$.

tested cPGCs (Fig. 2 E-H), whilst the negative control showed only a positive nuclear counter-staining and no nonspecific background fluorescence (Image not shown).

\section{PGC behavioral characters}

In response to $5 \mu \mathrm{g} / \mathrm{ml}$ SCF treatment, cPGCs showed three different morphological and migration behavior changes in terms of the formation of (a) cytoplasmic cycling and random plasma membrane blebbing with no migration, (b) a temporary membrane protrusions with random migration and (c) a persistent membrane protrusion with directional migration (Fig.3 B-G). The leading and lagging edges of the protrusion were clearly noticed on the migrating cPGCs, suggesting the establishment of membrane polarization (Fig.3 B-G).

All of the $\mathrm{CPGCs}$ and the RBCs in the control groups expressed only the cytoplasmic cycling behavior without any migration while $\sim 77.1 \%$ (54 out of 70 ) of the PGC population in the SCF-treated group presented membrane protrusions with active migration. Out of these migrating cPGCs, $48.1 \%$ (26 out of 54 ) showed persistent membrane protrusions, while the protrusions of the other $51 \%$ were only transient.

Following exposure to SCF (Fig. 3B), a spike/finger-like membrane protrusion was observed within $30 \mathrm{~min}$, beginning from a small projection and then obviously increasing in size at $1 \mathrm{~h}$ onwards. The persistent membrane protrusion showed a clear biased direction towards the highest SCF concentration from 1.5 $\mathrm{h}$ onwards and by 3 and $6 \mathrm{~h}$ of exposure to the SCF gradient the membrane protrusion was noticeably broad in shape and larger in size. In addition, in some cases single or multiple spike-like protrusions were transiently formed in different directions without ever developing into a broad protrusion and reformed in random directions. Pretreatment of the cPGCs with $10 \mu \mathrm{M}$ STI571, a selective Bcr-Abl tyrosine kinase and c-kit inhibitor, prior to the SCF treatment abrogated the SCF response with the CPGCs showing only the cytoplasmic cycling behavior, the same as in the control group (Fig. 3 A-G).

The average ratio of eccentricity $(E C)$ values at $0,0.5,1.0,1.5$, 2.0, 3.0 and $6.0 \mathrm{~h}$ are presented in Fig. 4, where the mean EC values of the control groups, both the SCF-unexposed cPGCs and the SCF-exposed RBCs remained close to unity throughout the test period, suggesting that the CPGC's and RBC's spherical morphology remained unchanged. The EC values of the SCFtreated cPGC group were significantly greater than those of the control groups $(p<0.05)$ and greater than 1 at all observation times, indicating the membrane protrusion and polarization in response to SCF treatment. Pretreatment of the cPGCs with STI571 abrogated the SCF-induced morphological alteration of the PGCs that instead retained the appearance of control cells with $\mathrm{EC}$ values close to unity.

\section{In vitro motility and chemotactic migration of $c P G C s$ in response to $\mathrm{SCF}$}

The migration indexes are reported in Table 1, where the cPGCs and the c-kit-negative RBCs of the control groups had a short deviation from their origin with negligible accumulated and Euclidean distances after a 16-h examination period. The velocity was, therefore, close to zero. However, significant accumulated and Euclidean distances were recorded with a measurable cell velocity in the SCF-treated CPGC group. The STI571 pretreatment resulted in a strong inhibition of the SCF-induced migration activities, with only tiny accumulated and Euclidean distances and almost zero velocity being recorded, and these were not statistically different from the control group.

The active PGC migration behavior was further examined

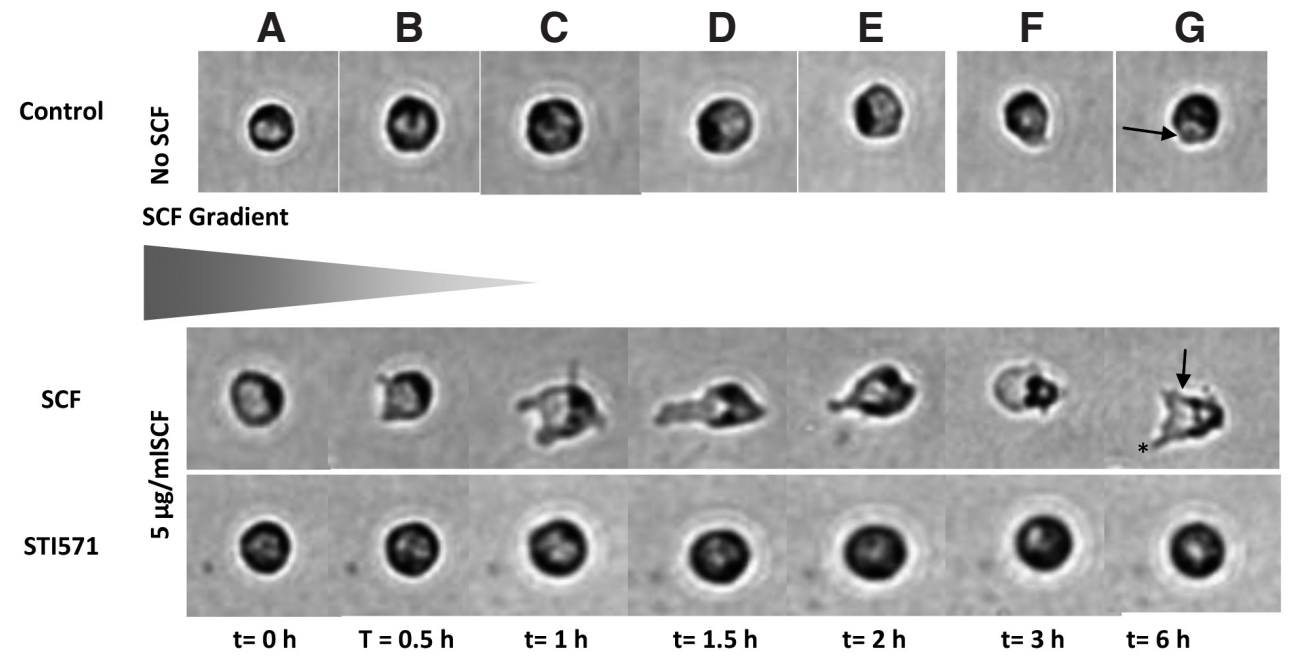

Fig. 3. Morphological changes in PGCs in response to an SCF gradient, as observed on Ibidi3D chemotaxis slides. PGC morphology over observation periods of (A) $0 \mathrm{~h}$, (B) $0.5 h$, (C) $1 h$, (D) $1.5 h$, (E) $2 h$, (F) $3 h$ and (G) $6 h$. (Control) The CPGCs exposed to KAv-1 medium without SCF showed cytoplasmic cycling and membrane blebbing (arrow head). (SCF) The SCF gradient was from the left side (highest concentration) to the right side (lowest concentration) of the observation area. Membrane polarization on the CPGCs was clearly revealed with a

defined leading edge directed towards the gradient. Lamellipodia-like (arrow head) and filopodia-like (*) structures were expressed. (STI571) The PGCs were pretreated with $10 \mu \mathrm{M}$ STI571 before exposure to the SCF gradient. A spherical cell shape remained without membrane polarization. 
TABLE 2

\section{CHEMOTAXIS INDEX}

\begin{tabular}{lcccccc} 
Treatment group & $\begin{array}{c}\text { Total number } \\
\text { of PGCs }\end{array}$ & coM $(\mu \mathrm{m})$ & Directness & FMlx & FMly & $\begin{array}{c}\text { (P-value) } \\
\text { Rayleigh test }\end{array}$ \\
\hline Control cPGCs & 51 & N/A & N/A & N/A & N/A & N/A \\
SCF-treated RBCs & 118 & N/A & N/A & N/A & N/A & N/A \\
SCF-treated cPGCs & 70 & 40.154 & 0.297 & -0.087 & 0.049 & 0.047 \\
$\begin{array}{l}\text { STI571-pretreated } \\
\text { cPGCs }\end{array}$ & 64 & N/A & N/A & N/A & N/A & N/A \\
\hline
\end{tabular}

$\mathrm{COM}=$ displacement of the center of mass. $\mathrm{N} / \mathrm{A}=$ Not applicable. $\mathrm{FMl} / \mathrm{y}=$ forward migration index in the $\mathrm{x}$ or $\mathrm{y}$ axis, respectively

for chemotaxis in terms of displacement of the center of mass (COM) means, directness, forward migration index and Rayleigh test (Table 2). However, since none of the cPGCs and RBCs in the control groups and the STI571 pretreated groups showed any migration, as based on the migration indexes (Table 1) and comparative COM (Fig. 5), the chemotaxis evaluation was not applicable. The Rayleigh test (based on $p<0.05$ ) indicated that SCF induced a chemotactic effect on the CPGC directional migration, where the trajectories of the SCF-treated cPGCs clearly depicted a directional migration towards the SCF concentration gradient (Fig. 6C). The trajectories of the control $\mathrm{CPGCs}$ and RBCs and STI571-pretreated cPGCs (Fig. 6 A, B and D) were hardly visible, with all the tested cPGCs and RBCs being located in close proximity to the origin and having deviation distances of less than the maximum diameter of the cells $(<20$ Im). Such distances are unlikely to be the result

Fig. 4 (Right). Primordial germ cell (PGC) polarization determined by the ratio of eccentricity (EC). cPGCs were exposed to $0 \mu \mathrm{g} / \mathrm{m} /$ SCF (- $-1,5 \mu \mathrm{g} / \mathrm{ml}$ SCF (***), a $10 \mathrm{Mm}$ STI571 pretreatment followed by $5 \mu \mathrm{g} / \mathrm{m} / \mathrm{SCF}(\longrightarrow)$ and $R B C$ s were exposed to $5 \mu \mathrm{g} / \mathrm{ml}$ $S C F(\rightarrow)$. Data are reported as the mean \pm SEM, from three repeats. Statistically significant differences within each time point at $\mathrm{p}<0.05$ and $\mathrm{p}<0.01$ are denoted by ${ }^{*}$ and ${ }^{*}$, respectively.

Fig. 5 (Right). Primordial germ cell (PGC) chemotactic migration, as determined by the displacement of center of mass (COM). CPGCs were exposed to $0 \mu \mathrm{g} / \mathrm{m} / \mathrm{SCF}(-\mathrm{C}-), 5 \mu \mathrm{g} / \mathrm{m} / \mathrm{SCF}(\cdots+*)$ ) a $10 \mu \mathrm{M}$ STI571 pretreatment followed by $5 \mu \mathrm{g} / \mathrm{m} / \mathrm{SCF} \rightleftharpoons$ ) and RBCs were exposed to $5 \mu \mathrm{g} / \mathrm{ml} \mathrm{SCF} \longrightarrow$. Data are reported as the mean COM, and the COM means were significantly increased in the SCF group but remained relatively unchanged in the control, STI571 and $R B C$ groups. of active migration but rather reflect the movement of cytoplasm.

\section{Discussion}

Successful migration of cPGCs in the developing gonads during early embryogenesis is extremely important for the production of germ cells and fertility in later life. Ectopic PCGs, as a result of defective migration, are subjected to apoptosis, possibly due to the lack of supporting environment including survival and proliferating factors in mice (Gu et al., 2009). A possible involvement of SCF/c-kit in the physiological phases of migrating PGCs has been suggested previously based on the positive c-kit expression on cPGCs and the SCF expression along the migratory pathway and in the genital ridges (Matsui et al., 1990). In chickens, the earliest detectable expression of c-kit on PGCs was reported at stage 17 of embryo development in the cell population that had already completed their migration and were localized in the gonads (Reedy et al., 2003). This, however, demonstrated an earlier c-kit expression by cPGCs at stage 14-15 embryos, suggesting that chicken PGCs are capable of SCF sensing before migration to the final target.

In the present in vitro study, SCF was the only external signal
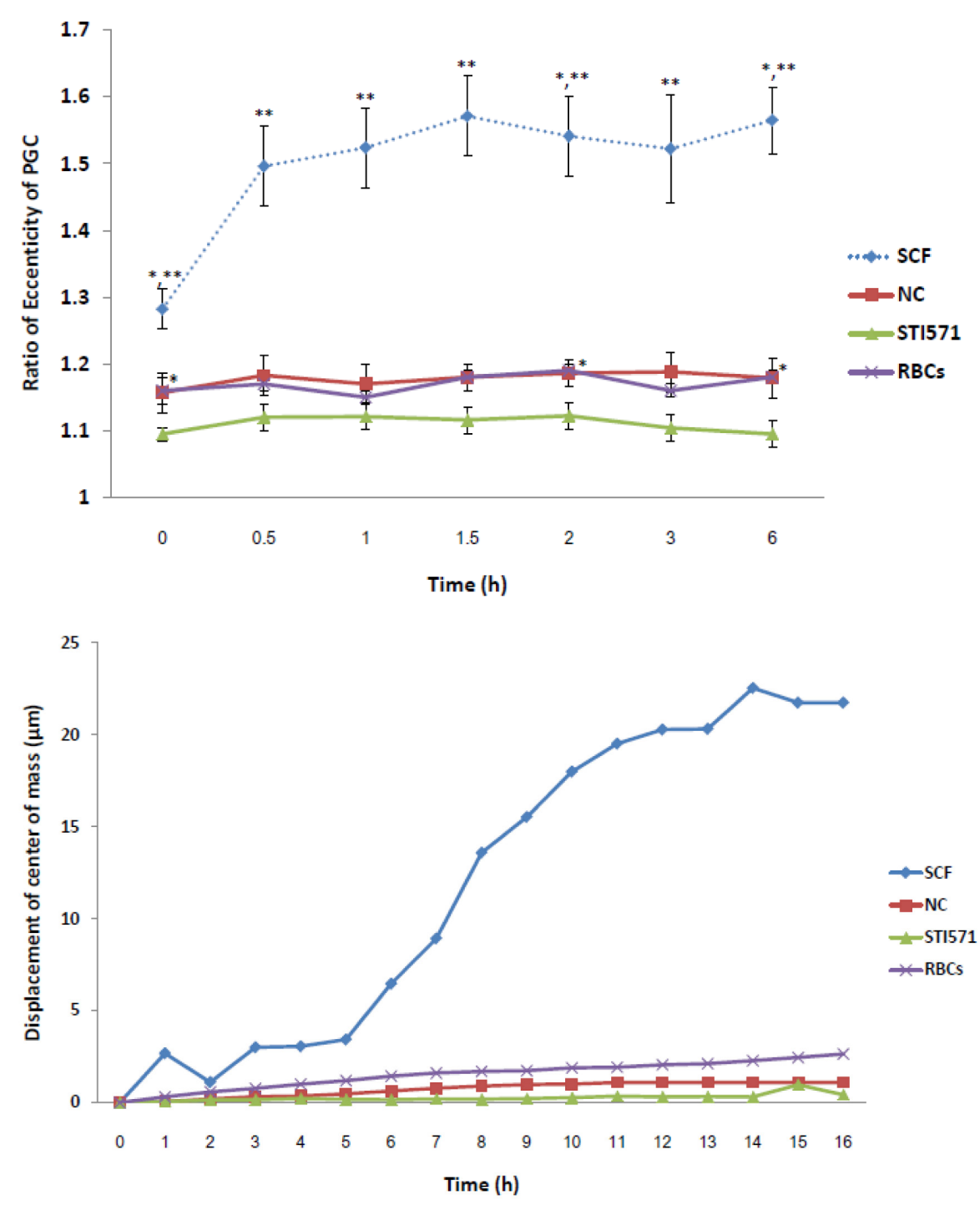
administered intentionally into the system. Instead of using collagen, as recommended for the ibidi 3D system, the cPGCs were embedded in low melting point (LMP) agarose because this nonphysiological substance has no recorded effect on CPGC migration or induction. In contrast, type I collagen has been reported to act as an adhesion molecule guiding the migration of several cell types including PGCs (Hesse et al., 2010). The media was serum free to prevent exposure to undefined chemokines potentially present in the serum (Zengel et al., 2011). Although the external mediators, except for the treatment factors, were omitted in the study system, the PGC behavior in the control group was not static. Dynamic cycling of the cytoplasm and random blebbings of the plasma membrane were visualized, which could be indicative of intrinsic activities of the $\mathrm{CPGCs}$, similar to those that were capable of migration and invasion (Ma and Baumgartner, 2013). The nonapoptotic membrane blebbings are known to be a cellular migration mechanism (reviewed in (Fackler and Grosse, 2008)). However, displacements of cPGCs in the control group were insignificant, suggesting a requirement for external contributed factor(s) for avian $\mathrm{CPGC}$ trafficking.

The cPGCs clearly responded to the SCF treatment by altering their morphology from a spherical to a polarized and elongated shape, characteristic of motile cells (reviewed in (Iglesias and Devreotes, 2008)). Indeed, the SCF-induced PGC polarization was evident as the formation of membrane protrusions and a significant increase in the mean EC value (Khandoga et al., 2009). Without SCFexposure, the EC values were almost constant at 1.0 indicating the normal round appearance of the PGCs. In the presence of the SCF gradient the protrusion was biased towards the highest SCF concentration, suggesting a chemotactic induction by SCF. Besides the significant accumulated and Euclidean distances of migration trajectories, the COM and Rayleigh tests were also significant, which strongly supported the chemotactic response of cPGCs to SCF (Zengel et al., 2011). This was supported by the STI571 pre-treatment, which completely abolished the SCF-induced morphological and behavioral changes as well as the migration of the cPGCs. The concentration of STI571 used in the present study $(10 \mu \mathrm{M})$ was reported to completely inhibit tyrosine kinase phosphorylation (Heinrich et al., 2000), and the formation of membrane protrusions and migration of human colon adenocarcinoma cells (PopowWozniak et al., 2011). STI571 has been reported to function as a selective Bcr-Abl tyrosine kinase inhibitor, which can be activated through several pathways, including the phosphatidylinositol-4,5-

Fig. 6. Primordial germ cell (PGC) and RBC trajectory plots over $16 \mathrm{~h}$ of observation. Migration trajectories of the CPGCs after exposure to (A) $0 \mu \mathrm{g} / \mathrm{m} / \mathrm{SCF}$ (control), with no significant movement; (B) RBCs were exposed to $5 \mu \mathrm{g} / \mathrm{ml} \mathrm{SCF}$, with no significant movement; (C) $5 \mu \mathrm{g} /$ $\mathrm{ml} \mathrm{SCF}$, where the PGC trajectories are mainly in the positive direction of the $y$-axis (the direction of the SCF gradient), and (D) $10 \mu \mathrm{M}$ STI571 pretreatment prior to exposure to $5 \mu \mathrm{g} / \mathrm{m} / \mathrm{SCF}$, where no significant migration trajectories of the CPGCs were visible.

bisphosphate 3-kinase ( $\mathrm{PI} 3 \mathrm{~K})$, and mitogen-activated protein kinases (MAPK) (reviewed in (Cilloni and Saglio, 2012). Accordingly the inhibition of the SCF-induced responses in the cPGCs by STI571 supports the role of SCF-induced c-kit phosphorylation in $\mathrm{CPGC}$ migration.

The negative responses to SCF treatments of the c-kit-negative RBCs also supported the function of SCF/c-kit in the chemotactic migration of CPGCs. A positive control using c-kit-positive nonPGC cells can not be conducted in this study due to a lack of the representative cell type with non-adherent character. The controls should be non-adherent cells like cPGCs so that the same study model and conditions can be applied. Without the positive control, whether the role of SCF/c-kit in migration induction is PGC specific can not be addressed by this study. Further investigation should be pursued when non-adherent c-kit positive cells are available.

Although the SCF-induced chemotactic effect was significant, the directness of migration was not that strong, where the movement towards the SCF gradient was far from in a straight line. This suggested that the migration efficiency of cPGCs would be rather low if solely under SCF guidance. However, the observed absence of a strongly uniform directness could reflect a nonuniform linear SCF gradient diffusion pattern in the experimental apparatus. Ibidi chemotaxis slide has been demonstrated to be able to maintain a long standing gradient for over $48 \mathrm{~h}$ (Zengel et al., 2011), which is considerably superior in this regard to other migration study systems, including transwell migration (Farini

\section{$A$} Control cPGCs $/ 0 \mu \mathrm{g} / \mathrm{ml} \mathrm{SCF}$

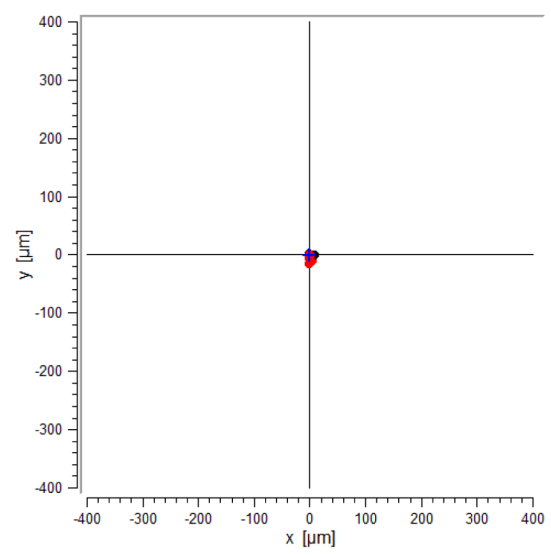

C

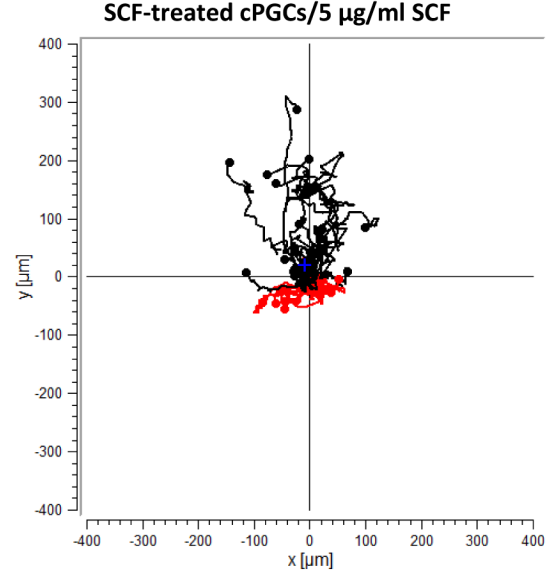

\section{B SCF-treated RBCs $/ 5 \mathrm{ug} / \mathrm{ml} \mathrm{SCF}$}

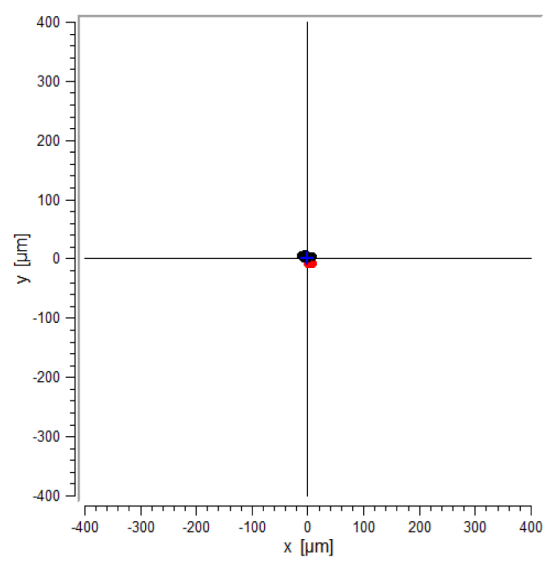

D

STI571-pretreated cPGCs $/ 5 \mu \mathrm{g} / \mathrm{ml} \mathrm{SCF}$

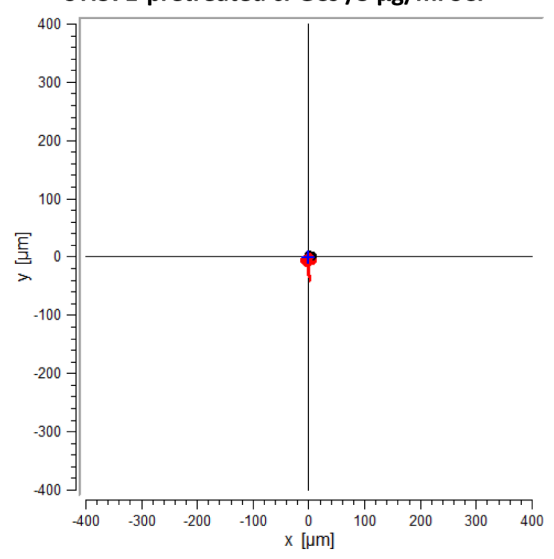



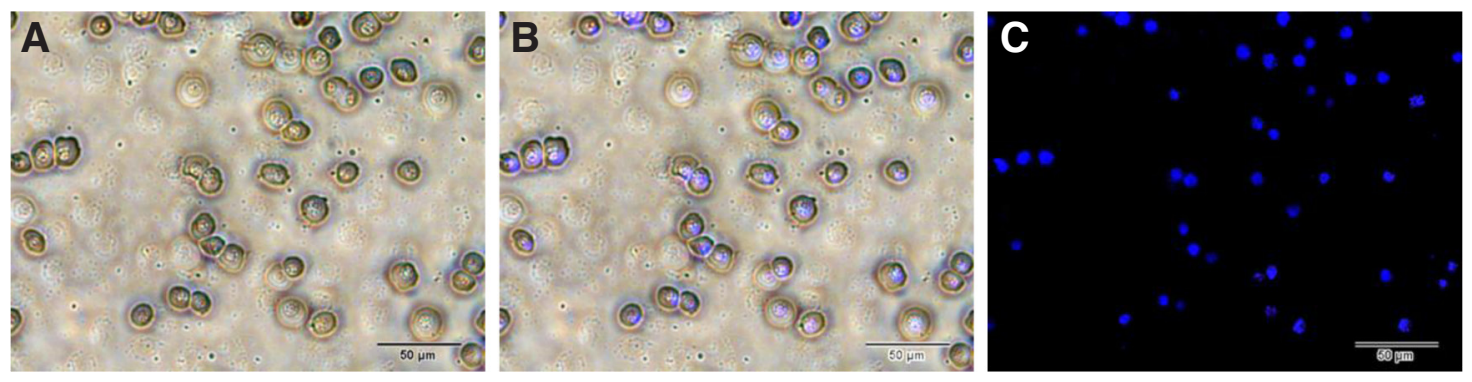

Fig. 7. Microscopic images (400x magnification) of paraformaldehyde-fixed blood cells collected from chicken embryos at stages 14-15 of development. (A) Phase-contrast images. (B) Merged images of blood cells with phase-contrast images and nuclear staining with Hoechst 33342 (dark blue color). (C) Negative c-kit and nuclear counterstaining with Hoechst 33342. Image format was pixels. Scale bars represent 50 um.

et al., 2007). Previously, SDF-1 was suggested to function as a chemoattractant in the late migration of chicken cPGCs (Stebler et al., 2004), and chicken cPGCs have been shown to preferentially glide along the longitudinal axis of feeder cells (Kuwana, 1993), implying the topographical association with the ground matrix. It is conceivable that the efficient trafficking of avian PGCs requires a coordination of multiple factors similar to the findings in mice, humans and zebrafish. Generally, PGC migration is a function of the propulsion and repulsion induced forces of chemokines and adhesion molecules, such as SDF-1, SCF, e-cadherin and integrin (reviewed in (Richardson and Lehmann, 2010)). Besides the previously reported SDF-1 (Stebler et al., 2004) and herein reported SCF chemotactic functions, other influencing factors and their interactions on PGC migration in avian await further scrutiny.

Research into the controlling mechanisms of the directional migration of PGCs has focused on the chemoattractant factors being released from the gonadal stromal cells (Kuwana et al., 1986). Since cPGCs show membrane projections extending directly towards the genital ridges this is suspected to be the release site of putative chemoattractant(s) (Kuwana et al., 1986). In the phase of PGC migration at stages 8-22, SCF has been found to be positively expressed in the lateral and intermediate mesoderm (Reedy et al., 2003), part of which develops later in embryogenesis into the gonadal anlagen. Therefore, the present study addressed the potential chemotactic effect of soluble SCF, based upon its potential production and release from the developing gonadal anlagen, to attract CPGC in migration. Although the gonadal stromal cells have been suggested to control the positioning precision they are dispensable for the directional migration in the migration process of mouse PGCs (Chen et al., 2013).

Interestingly, the non-uniform SCF-induced cPGC migration found in the present study might indicate the existence of different subpopulations of cPGCs with potentially different physiological properties. Approximately two-thirds of the PGCs were found to respond to the SCF treatment by expressing membrane protrusions indicative of migrating cells. The remaining non-responding PGCs are unlikely to be due to significant damage, abnormalities or death since their general morphology remained intact and viable with active cytoplasmic cycling visible as in the control group of cells without SCF or STI571 exposure. The SCF-responding cells could be subdivided into two groups in terms of the SCF-induced membrane protrusions being either transient multiple narrow protrusions or a single persistent broad protrusion. The PGCs with the latter character were able to perform a directional migration while the movement of those with the former character was rather random and inefficient. These two subpopulations could represent PCGs at different developmental stages as they undergo proliferation during migration (Nakamura et al., 2007). As such, this might be related to the findings that the transmigration of mouse PGCs into the gonadal anlagen is not simultaneous but gradually begins at stage 15 and extends to approximately stage 29 (reviewed in (Nieuwkoop and Sutasurya, 1979)).

Within migrating mouse PGCs a heterogeneity in c-kit expression levels has been reported, varying from non-detectable to weak and strong levels (Morita-Fujimura et al., 2009). In chickens, the levels of c-kit expression on gonadal PGCs of developing embryos was found to increase from stage 17 to stage 19 and then was undetectable at stage 22 (Reedy et al., 2003). The varying c-kit expression between gonadal PGCs, if also the case in the cPGCs, might explain the variation in the SCF-induced migration observed in the present study. Accordingly, the different patterns of membrane protrusions leading to different migration responses to SCF could be a function of the developmental heterogeneity of the cPGCs. The immunocytochemistry used in the present study was, however, only suitable for positive / negative discrimination of c-kit expression and not for quantitative analysis. Future quantitative evaluation of c-kit expression levels could contribute some useful information towards a better understanding of the physiological phases of cPGCs in Aves. Future detailed characterizations of the physiological related markers of the cPGCs should significantly contribute to the understanding of PGC migration mechanisms.

SCF exerts a chemotactic function on various cell types, including hematopoietic stem cells, neural crest cells and melanocytes (reviewed in (Lennartsson and Ronnstrand, 2012)) as well as mouse PGCs (Gu et al., 2009). The SCF-induced formation of membrane polarization and protrusion involves reorganization of a number of cytoskeletal proteins, particularly F-actin, leading to the formation of the locomotory lamellipodia and filopodia (Farini et al., 2007). Signaling pathways of SCF/c-kit in mouse PGCs have been identified to involve mTor downstream of Ras, Src and PI3K (De Miguel et al., 2002). The factors that regulate PGC migration, including transcript mRNA and proteins, might be differently expressed in individual PGCs (reviewed in (Richardson and Lehmann, 2010)), which could be part of the explanation of the response variation found. Downstream signaling of SCFjc-kit induced migration of avian PGCs should then be further examined.

In conclusion, a chemotactic role of SCF/c-kit in the migration of avian CPGC could be suggested from the present study. The direct evidence was shown that SCF/c-kit is one of the chemotactic elements for PGCs throughout the interstitial their migration in vitro. 
Besides contributing to fundamental developmental embryology, we anticipate the ability to make use of these findings to facilitate the gonadal migration of the transplanted PGCs and so improve the production of germline chimera.

\section{Materials and Methods}

\section{PGC isolation, enrichment and characterization}

Fertilized chicken eggs were obtained from a local hatchery and were incubated at $38^{\circ} \mathrm{C}$ until the embryos reached the Hamburger and Hamilton stage $(\mathrm{HH}) 14-15$ of development, after some $50-56 \mathrm{~h}$ of incubation (Hamburger and Hamilton, 1992). Under a stereoscope (SZ51, Olympus), a blood sample was collected from the sinus terminalis and omphalomesenteric (vitelline) arteries of each embryo using a glass capillary pipette with an approximately $50 \mu \mathrm{m}$ tip diameter. The PGCs were isolated from the blood cells by double density gradient centrifugation, using a protocol modified from (Zhao and Kuwana, 2003). Briefly, the blood sample was gently loaded onto $5.5 \%$ and $11 \%$ nycodenz and then centrifuged at $400 \mathrm{~g}$, $4^{\circ} \mathrm{C}$ for $30 \mathrm{~min}$. The PGC suspended fraction was collected, washed and re-suspended in phosphate buffered saline (PBS) pH 7.4. Enrichment of the cPGCs was performed by a selective aspiration of the cPGCs under an inverted phase contrast microscope (IX502, Olympus). The selection was based on the distinguishable morphology of cPGCs of being round, large cells with a diameter range of 10-22 $\mu \mathrm{m}$ (Yasuda et al., 1992), an extremely eccentric nucleus and abundant cytoplasmic granules that appear reflective under dark field illumination. The enriched cPGC suspension was pelleted by centrifugation at $800 \mathrm{~g}$ for $10 \mathrm{~min}$, removing the supernatant and keeping the pellet on ice for further characterization using PAS staining and immunofluorescent detection of SSEA-1. The expression of c-kit on the CPGCs was examined for its capacity for SCF sensing.

\section{PAS staining and indirect immunofluorescence staining of the SSEA-1 and c-kit receptor \\ The enriched PGCs were embedded in a rat-tail collagen gel mix} containing $0.5 \mu \mathrm{g} / \mathrm{ml}$ rat-tail collagen, and $7.5 \%$ (w/v) NaHCO3 in KAv-1 medium. Briefly, the ice-cold rat-tail collagen gel mix was added to the PGC pellet, mixed and allocated into three molds. The molds were prepared in a 96-well plate by half-filling the wells with a $2 \%$ (w/v) LMP agarose gel and then cutting off the solidified gel at the center of each well to make a circular mold of $5 \mathrm{~mm}$ in diameter. The plate with the embedded PGCs was placed on ice for 10 minutes before being transferred to $22^{\circ} \mathrm{C}$ to allow gradual gelation for 45 minutes. The embedded PGCs were fixed with $4 \%$ $(w / v)$ paraformaldehyde for 20 minutes and washed thrice, 15 min each with PBS pH 7.4. The fixed embedded cPGCs were then subjected to PAS staining, and SSEA-1 and c-kit receptor indirect immunofluorescent staining.

The PAS staining was performed according to the standard histochemical staining procedure. To detect the SSEA-1 marker, the embedded cPGCs were incubated with 1:50 mouse monoclonal anti-SSEA-1 (Santa Cruz Biotechnology, USA) in PBS pH 7.4 overnight at $4^{\circ} \mathrm{C}$, then washed thrice in PBS pH 7.4. A secondary antibody, 1:1000 FITC conjugated goat anti-mouse IgM (Santa Cruz Biotechnology, CA, USA) in PBS pH 7.4 was applied for $2 \mathrm{~h}$ at room temperature before the washing steps. Nuclear counterstaining was performed using $5 \mu \mathrm{g} / \mathrm{ml}$ Hoechst 33342 (Sigma, USA) in PBS pH 7.4 for $10 \mathrm{~min}$ and washed once with PBS pH 7.4. For c-kit detection, the CPGCs were subjected to an overnight incubation at $4^{\circ} \mathrm{C}$ with a 1:50 polyclonal goat anti-mouse c-kit primary antibody (M14, Santa Cruz Biotechnology, CA, USA) in PBS (PBS pH 7.4 containing $0.1 \%(\mathrm{w} / \mathrm{v})$ saponin and $1 \%(\mathrm{w} / \mathrm{v})$ bovine serum albumin). The cells were then washed thrice in PBS, 15 min each and were incubated for $2 \mathrm{~h}$ at room temperature with 1:1000Alexa® Fluor568 conjugated donkey anti-goat IgG $(\mathrm{H}+\mathrm{L}$; Molecular Probes, Life technologies, USA) in PBSW. After triple washing in PBS the cells were nuclear counterstained with Hoechst 33342 (Sigma, USA) as above. For both immunofluorescent detections, negative controls were performed as above except with the primary antibodies being omitted. Results were observed under an inverted fluorescence microscope (DP72-BSW, Olympus).

\section{Chemotaxis assays}

Ibidi ${ }^{3 \mathrm{D}}$ chemotaxis slides (Ibidi GmbH) were used as an in vitro model to investigate the chemotactic activity of cPGC in the presence of recombinant chicken SCF. The SCF was a gift from Dr. Bartunek, the production and characterization of which have been reported previously (Bartunek et al., 1996). The LMP agarose (Invitrogen, USA) gel was selected as the matrix to support the horizontal migration of the CPGCs, which is non-adherent by nature. Triplicate experiments were performed; each including the SCF-treated, negative control and STI571-pretreated then SCF-treated groups. Briefly, freshly enriched PGCs were gently mixed with $0.5 \%(\mathrm{w} / \mathrm{v})$ LMP in serum-deprived KAv-1 medium. The cell mixture was subsequently loaded on the observation area in the middle channel, which was a gap connected to the two parallel reservoirs on either side. The chamber was chilled at $10^{\circ} \mathrm{C}$ for 30 min to allow gelation and was then placed on a thermostage providing a constant temperature of $38^{\circ} \mathrm{C}$. The thermo-stage was attached to an inverted phase-contrast microscope equipped with a CCD camera and time-lapse photography (DP72-BSW, Olympus). For the SCF-treated group the SCF gradient across the observation area in the middle channel was generated by filling one reservoir with $5 \mu \mathrm{g} / \mathrm{ml} \mathrm{SCF}$ in serum-deprived KAv-1 medium and the other with the same medium except without SCF. Note that the concentration of SCF used in the assay $(5 \mu \mathrm{g} / \mathrm{ml})$ was selected from preliminary experiments to determine the SCF efficacy for inducing cPGC migration in this experimental system (Data not shown). The control group was treated as per the SCF-treated group above except both reservoirs were filled with serum-deprived KAv-1 medium and no SCF. Finally, the STI571inhibited group, used to confirm the effects of SCF, was performed as per the SCF-group above except that the CPGCs were first pretreated by incubating with $10 \mu \mathrm{M}$ STI571 for 30 min before being suspended in the gel matrix and subjected to the SCF-gradient migration examination as above.

A set of negative control experiments, using c-kit-negative cells was conducted to support the function of SCF/c-kit in chemotactic migration. The packed RBCs remaining after separating the CPGCs and other nycodenz suspended cells were tested negative for c-kit expression by the immunofluorestcent staining (Fig. 7), thereby being examined as another negative control for SCF/c-kit induction of migration. The experiments were conducted similarly to those on cPGCs.

In all cases sequential digital photographs were taken every 2 min over the 16 -h period and at $0,0.5,1.0,1.5,2.0,3.0$ and $6.0 \mathrm{~h}$ the morphologica changes and membrane polarization of the PGCs were evaluated based on

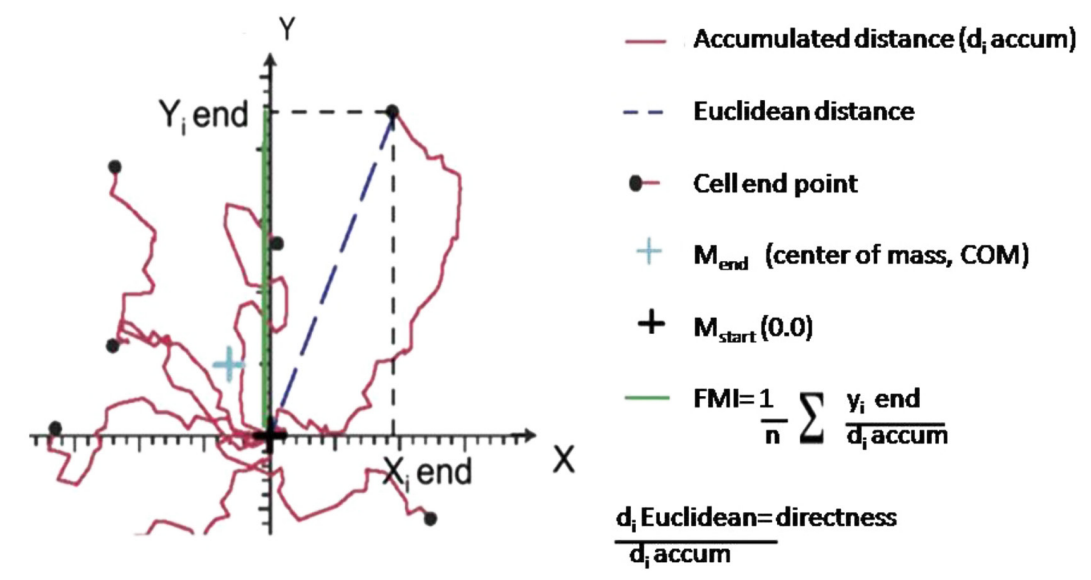

Fig. 8. Trajectory plot defining different parameters for analyzing chemotaxis in vitro in 3D model. 
the formation of membrane extension(s) and the EC ratio, which is equal to the ratio of the major axis of the cell, the longest straight line that can be drawn across the cell, and the minor axis, the longest straight line that can be drawn across the cell at $90^{\circ}$ to the major axis (Khandoga et al., 2009). The cPGCs with membrane protrusions and an EC of significantly greater than 1 were elementarily defined as polarized PGCs

Cell tracking was performed using the Image $J$ 'Manual Tracking' plug-in software (rsbweb.nih.gov; Ibidi $\mathrm{GmbH}$ ). Cellular mobility and chemotactic migration were evaluated based on accumulated and Euclidean distances, cell velocity, COM, forward migration index (FMI), directness (Fig. 8) and Rayleigh test $(p<0.05)$, using the 'Chemotaxis and Migration Tool 2.0' plug-in software (Ibidi GmbH).

\section{Statistical analysis}

The migratory assay was performed in triplicate and the data of each treatment were pooled and then analyzed for compliance with a normal distribution by the Shapiro-Wilk's test. Results are expressed as the mean \pm standard error of the mean (SEM). Since the data were found to not be normally distributed, Kruskal-Wallis One-way Analysis of Variance by Rank test was used to assess statistical differences, using the SPSS software (SPSS version 21; SPSS Inc.; Chicago, IL, USA). The Bonferroni-corrected Mann-Whitney $U$ test was used to compare the significance of differences between means, accepting a $p$ value of $<0.05$ as significant.

\section{Acknowledgements}

This study was funded by NRCT-JSPS joint project and Kasetsart University Research and Development Institute. Recombinant chicken SCF was a kind gift from Dr. Bartunex, Institute of Molecular Pathology, Vienna, Austria. Chicken embryos were donated by CPF (Thailand) Public Company Limited.

\section{Reference}

ANDERSON, R., COPELAND, T.K., SCHOLER, H., HEASMAN, J. and WYLIE, C. (2000). The onset of germ cell migration in the mouse embryo. Mech Dev91:61-68.

ARA, T., NAKAMURA, Y., EGAWA, T., SUGIYAMA, T., ABE, K., KISHIMOTO, T., MATSUI, Y. and NAGASAWA, T. (2003). Impaired colonization of the gonads by primordial germ cells in mice lacking a chemokine, stromal cell-derived factor-1 (SDF-1). Proc Natl Acad Sci USA 100: 5319-5323.

BARTUNEK, P., PICHLIKOVA, L., STENGL, G., BOEHMELT, G., MARTIN, F.H., BEUG, H., DVORAK, M. and ZENKE, M. (1996). Avian stem cell factor (SCF): production and characterization of the recombinant His-tagged SCF of chicken and its neutralizing antibody. Cytokine 8: 14-20.

CHEN, Y., XU, J., LIU, S. and HOU, X. (2013). Electroacupuncture at ST36 Increases Contraction of the Gastric Antrum and Improves the SCF/c-kit Pathway in Diabetic Rats. Am J Chin Med 41: 1233-1249.

CILLONI, D. and SAGLIO, G. (2012). Molecular pathways: BCR-ABL. Clin Cancer Res 18: 930-937.

DE MIGUEL, M.P., CHENG, L., HOLLAND, E.C., FEDERSPIEL, M.J. and DONOVAN, P.J. (2002). Dissection of the c-Kit signaling pathway in mouse primordial germ cells by retroviral-mediated gene transfer. Proc Natl Acad Sci USA 99: 10458-10463.

EYAL-GILADI, H., GINSBURG, M. and FARBAROV, A. (1981). Avian primordial germ cells are of epiblastic origin. J Embryol Exp Morphol 65: 139-147.

FACKLER, O.T. and GROSSE, R. (2008). Cell motility through plasma membrane blebbing. J Cell Biol 181: 879-884.

FARINI, D., LASALA, G., TEDESCO, M. and DE FELICI, M. (2007). Chemoattractant action and molecular signaling pathways of Kit ligand on mouse primordial germ cells. Dev Biol 306: 572-583.

GU, Y., RUNYAN, C., SHOEMAKER, A., SURANI, A. and WYLIE, C. (2009). Steel factor controls primordial germ cell survival and motility from the time of their specification in the allantois, and provides a continuous niche throughout their migration. Development 136: 1295-1303.

HAMBURGER, V. and HAMILTON, H.L. (1992). A series of normal stages in the development of the chick embryo. 1951. Dev Dyn 195: 231-272.
HEINRICH, M.C., GRIFFITH, D.J., DRUKER, B.J., WAIT, C.L., OTT, K.A. and ZIGLER, A.J. (2000). Inhibition of c-kit receptor tyrosine kinase activity by STI 571, a selective tyrosine kinase inhibitor. Blood 96: 925-932.

HESSE, E., HEFFERAN, T.E., TARARA, J.E., HAASPER, C., MELLER, R., KRETTEK, C., LU, L. and YASZEMSKI, M.J. (2010). Collagen type I hydrogel allows migration, proliferation, and osteogenic differentiation of rat bone marrow stromal cells. $J$ Biomed Mater Res A 94: 442-449.

IGLESIAS, P.A. and DEVREOTES, P.N. (2008). Navigating through models of chemotaxis. Curr Opin Cell Biol 20: 35-40.

KHANDOGA, A.G., KHANDOGA, A., REICHEL, C.A., BIHARI, P., REHBERG, M. and $\mathrm{KROMBACH}, \mathrm{F}$. (2009). In vivo imaging and quantitative analysis of leukocyte directional migration and polarization in inflamed tissue. PLoS One 4: e4693.

KUWANA, T. (1993). Migration of Avian Primordial Germ Cells toward the Gonadal Anlage. Dev Growth Diff 35: 237-243.

KUWANA, T., MAEDA-SUGA, H. and FUJIMOTO, T. (1986). Attraction of chick primordial germ cells by gonadal anlage in vitro. Anat Rec 215: 403-406.

LENNARTSSON, J. and RONNSTRAND, L. (2012). Stem cell factor receptorjc-Kit: from basic science to clinical implications. Physiol Rev 92: 1619-1649.

MA, M. and BAUMGARTNER, M. (2013). Filopodia and membrane blebs drive efficient matrix invasion of macrophages transformed by the intracellular parasite Theileria annulata. PLoS One 8: e75577.

MAMSEN, L.S., BROCHNER, C.B., BYSKOV, A.G. and MOLLGARD, K. (2012). The migration and loss of human primordial germ stem cells from the hind gut epithelium towards the gonadal ridge. Int J Dev Biol 56: 771-778.

MATSUI, Y., ZSEBO, K. and HOGAN, B.L. (1992). Derivation of pluripotential embryonic stem cells from murine primordial germ cells in culture. Cell 70: 841-847.

MATSUI, Y., ZSEBO, K.M. and HOGAN, B.L. (1990). Embryonic expression of a haematopoietic growth factor encoded by the SI locus and the ligand for c-kit. Nature 347: 667-669.

MORITA-FUJIMURA, Y., TOKITAKE, Y. and MATSUI, Y. (2009). Heterogeneity of mouse primordial germ cells reflecting the distinct status of their differentiation, proliferation and apoptosis can be classified by the expression of cell surface proteins integrin alpha6 and c-Kit. Dev Growth Diff 51: 567-583.

NAKAMURA, Y., YAMAMOTO, Y., USUI, F., MUSHIKA, T., ONO, T., SETIOKO, A.R., TAKEDA, K., NIRASAWA, K., KAGAMI, H. and TAGAMI, T. (2007). Migration and proliferation of primordial germ cells in the early chicken embryo. Poult $\mathrm{Sc} i$ 86: 2182-2193.

NIEUWKOOP, P. and SUTASURYA, L. (1979). In "Primordial Germ Cells in the Chordates; embryogenesis and phylogenesis", (ed. ED BY M ABERCROMBIE, D. N., JG TORREY), Cambridge: Cambridge University Press, pp. 1-187.

POPOW-WOZNIAK, A., WOZNIAKOWSKA, A., KACZMAREK, L., MALICKABLASZKIEWICZ, M. and NOWAK, D. (2011). Apoptotic effect of imatinib on human colon adenocarcinoma cells: influence on actin cytoskeleton organization and cell migration. Eur J Pharmacol 667: 66-73.

REEDY, M.V., JOHNSON, R.L. and ERICKSON, C.A. (2003). The expression patterns of c-kit and $\mathrm{SI}$ in chicken embryos suggest unexpected roles for these genes in somite and limb development. Gene Expr Patterns 3: 53-58.

RICHARDSON, B.E. and LEHMANN, R. (2010). Mechanisms guiding primordial germ cell migration: strategies from different organisms. Nat Rev Mol Cell Biol 11:37-49.

SOTO-SUAZO, M. and ZORN, T.M. (2005). Primordial germ cells migration: morphological and molecular aspects Anim Reprod 2: 147-160.

STEBLER, J., SPIELER, D., SLANCHEV, K., MOLYNEAUX, K.A., RICHTER, U., COJOCARU, V., TARABYKIN, V., WYLIE, C., KESSEL, M. and RAZ, E. (2004). Primordial germ cell migration in the chick and mouse embryo: the role of the chemokine SDF-1jCXCL12. Dev Biol 272: 351-361.

YASUDA, Y., TAJIMA, A., FUJIMOTO, T. and KUWANA, T. (1992). A method to obtain avian germ-line chimaeras using isolated primordial germ cells. $J$ Reprod Fertil 96: 521-528.

ZENGEL, P., NGUYEN-HOANG, A., SCHILDHAMMER, C., ZANTL, R., KAHL, V. and HORN, E. (2011). mu-Slide Chemotaxis: a new chamber for long-term chemotaxis studies. BMC Cell Biol 12: 21.

ZHAO, D.F. and KUWANA, T. (2003). Purification of avian circulating primordial germ cells by nycodenz density gradient centrifugation. Br Poult Sci 44: 30-35. 


\section{Further Related Reading, published previously in the Int. J. Dev. Biol.}

The migration and loss of human primordial germ stem cells from the hind gut epithelium towards the gonadal ridge Linn Salto Mamsen, Christian Beltoft Brøchner, Anne Grete Byskov and Kjeld Møllgard

Int. J. Dev. Biol. (2012) 56: 771-778

Regulation of cell fate determination by Skp1-Cullin1-F-box (SCF) E3 ubiquitin ligases Christopher J. Hindley, Gary S. McDowell, Helen Wise and Anna Philpott Int. J. Dev. Biol. (2011) 55: 249-260

The role of stem cell factor and of alternative c-kit gene products in the establishment, maintenance and function of germ cells. C Sette, S Dolci, R Geremia and P Rossi

Int. J. Dev. Biol. (2000) 44: 599-608

Regulation of primordial germ cell development in the mouse.

M De Felici

Int. J. Dev. Biol. (2000) 44: 575-580

Causes and consequences of apoptosis in spermatozoa; contributions to infertility and impacts on development

R. John Aitken and Mark A. Baker

Int. J. Dev. Biol. (2013) 57: 265-272

Coordinated modulation of cellular signaling through ligand-gated ion channels in Hydra vulgaris (Cnidaria, Hydrozoa)

Paola Pierobon

Int. J. Dev. Biol. (2012) 56: 551-565

Bimodal distribution of motility and cell fate in Dictyostelium discoideum Pavana Goury-Sistla, Vidyanand Nanjundiah and Gopal Pande Int. J. Dev. Biol. (2012) 56: 263-272

Signaling networks in cancer - an interview with Christian Gespach Olivier De Wever

Int. J. Dev. Biol. (2011) 55: 713-718

5 yr ISI Impact Factor $(2013)=2.879$

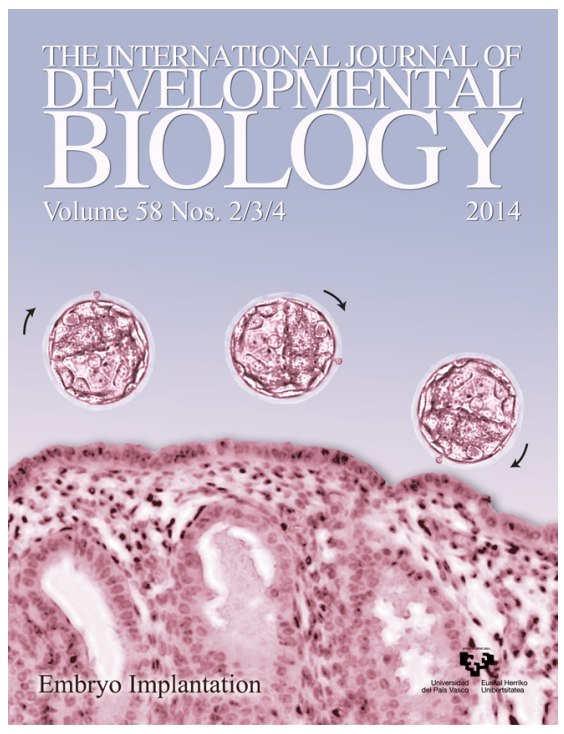

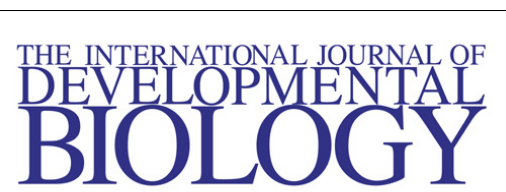

Volume 48 Nos. $5 / 6$ Special issue

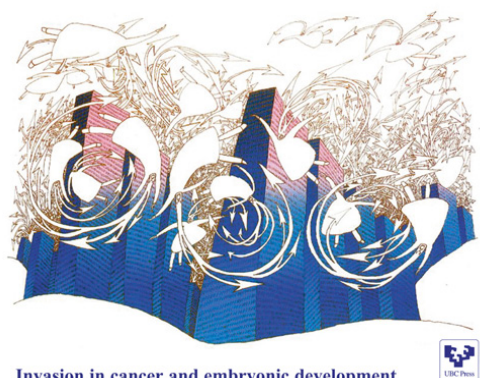

Invasion in cancer and embryonic development 5

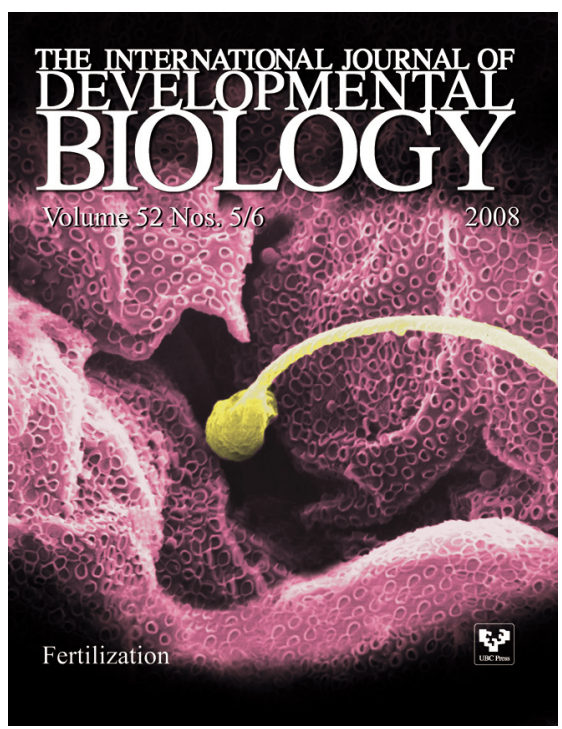

